\title{
The Relationship Context of Contraceptive Use At First Intercourse
}

\author{
By Wendy D. Manning, Monica A. Longmore and Peggy C. Giordano
}

Context: Despite widespread efforts to increase contraceptive use to prevent both pregnancy and sexually transmitted diseases among sexually active adolescents, most prior work examining adolescent contraceptive use does not explicitly recognize that sexual decision-making inherently involves both partners in a couple.

Methods: An analytic sample of 1,593 females who first had intercourse during adolescence (prior to age 18) was drawn from the 1995 National Survey of Family Growth. Logistic regression and multinomial logistic regression techniques were used to model the effects of sexual partners' characteristics and relationship type on contraceptive use at first intercourse and contraceptive method selected at first intercourse.

Results: Approximately $31 \%$ of respondents used no contraceptive method at first intercourse. Roughly half (52\%) of adolescents who had just met their sexual partner used no method, compared with $24 \%$ of those who were going steady. Whereas $75 \%$ of teenagers who practiced contraception at first intercourse used a condom, $17 \%$ relied on the pill. In multivariate models, net of other variables, adolescents who had just met their partner had $66 \%$ lower odds than those who were going steady of practicing contraception at first intercourse. Individual-level factors that influenced contraceptive use at first intercourse were age at first intercourse, race or ethnicity, family type, parents' education, grades in school and receipt of birth control education prior to first intercourse. Differences between respondents and their partner in age and race or ethnicity mostly were not significantly related to method use at first intercourse. One exception was that adolescents who first had sex with a man six or more years older had reduced odds of practicing contraception. Type of relationship was significantly associated with method selection only among adolescents who were just friends with their first partner, who had higher odds of using "other" methods rather than the condom. Variables associated with pill use rather than condom use were age at first sex, race, family type, mother's education and school grades.

Conclusions: Further efforts to understand contraceptive choice among adolescents should focus on relationship features. Research on the decision-making process surrounding contraceptive use may benefit from treating this as a partner decision and not just as a decision made by one member of the couple. Further research examining the qualities of the relationship may provide important clues for understanding adolescent contraceptive choice.

Family Planning Perspectives, 2000, 32(3):104-110

$\mathrm{D}$ espite societal efforts to reduce adolescent sexual activity, most adolescents have had sexual intercourse by the time they reach adulthood. ${ }^{1}$ Analysis of the Youth Risk Behavior Surveys reveals that in 1997, 61\% of high school seniors reported ever having had sex. ${ }^{2}$ These levels of teenage sexual activity reinforce the importance of promoting the use of contraceptives to prevent both adolescent pregnancy and the spread of sexually transmitted diseases (STDs).

Contraceptive use has risen among adolescents, with condoms and the pill being the most popular methods. ${ }^{3}$ Among teenagers, the most common method reported at first intercourse is the condom. ${ }^{4}$ Although this method requires the cooperation and agreement of both sexual partners, prior work has often treated contraceptive choice as an individual decision. Thus, the relationship context of adolescents' sexual decision-making warrants additional research.

Previous studies demonstrate that adolescents in dating relationships initiate sex earlier, ${ }^{5}$ but the effect of the type of relationship with first sexual partner (e.g., ac- quaintance, exclusively dating or engaged) on adolescent contraceptive use has not been clearly established. Prior work that considered the effect of relationship type on contraceptive use has been largely limited to either clinic samples of adolescents or samples of adults. The few studies that relied on national samples analyzed only the male perspective. Moreover, the results of these prior studies are mixed.

Some studies have concluded that couples in closer relationships are more likely to practice contraception than are their counterparts in more casual relationships. Adolescents in closer relationships may be more aware that their relationship could become sexual, and as a result may be more prepared for a sexual encounter. Furthermore, communication levels may be higher in closer relationships, and greater contraceptive use has been found to be associated with higher levels of communication. $^{6}$

In a purposive sample of young adults, contraceptive use was found to be greater among more committed couples and among young adult men who had a closer relationship with their first sexual partner. ${ }^{7}$ Higher levels of involvement with sexual partners were indirectly positively related to contraceptive use among college-age men. ${ }^{8}$ Focus-group results indicate that men in long-term, stable relationships who have strong emotional ties to their partner were more likely than those in casual relationships to discuss, support and practice contraception. ${ }^{9}$ In particular, greater condom use has been reported

Wendy D. Manning is assistant professor, Monica A Longmore is associate professor and Peggy C. Giordano is professor, Department of Sociology, Bowling Green State University, Bowling Green, $\mathrm{OH}$. The authors appreciate Debarun Majumdar's careful research assistance. The research on which this article is based was supported by a grant from the National Institute of Child Health and Human Development (grant HD36223). 
among young men (ages 17-21) who have closer relationships with their first sexual partner. ${ }^{10}$ Similarly, black women in a street survey reported more condom use when they felt more emotionally close to their partner. ${ }^{11}$ At the bivariate level, young women who were engaged or going steady with their most recent sexual partner were more likely to practice contraception. ${ }^{12}$ Reliable contraceptive use has even been found to be associated with specific styles of expressing love, with young adults who report more romantic, erotic attitudes toward love also reporting more reliable contraceptive use. ${ }^{13}$

Yet other evidence does not support the positive association between contraceptive use and relationship closeness. For example, adolescent males' condom use with their most recent sexual partner was not related to the duration of their relationship with that partner. ${ }^{14}$ Additionally, the level of partner involvement was not related to contraceptive use among a purposive sample of college-age women. ${ }^{15}$ A slightly different measure of contraceptive use- consistency of condom use with recent sexual partners-was not related to type of relationship in analyses of the National Survey of Adolescent Men, ${ }^{16}$ as well a clinical sample of adolescents. ${ }^{17}$

In fact, some studies have found a negative association between closeness with a sexual partner and contraceptive use. Young men who later entered a committed relationship with their sexual partner were less likely than those who did not to use condoms at first intercourse with that partner. ${ }^{18}$ Adult men in more casual relationships (dating, rather than cohabitation or marriage) were more likely to use protection against STDs. ${ }^{19}$ Similarly, focusgroup discussions revealed that the more casual the relationship, the more likely men were to choose condoms, particularly to protect themselves against STDs. ${ }^{20}$

Characteristics of the sexual partner are another dimension of the relationship context. The partner's social and demographic features may be particularly influential for contraceptive use at first intercourse, as opposed to method use at later intercourse. More importantly, given gendered patterns of sexual behavior, the male's characteristics may have an especially strong impact on contraceptive decision-making. Two strategies have been used to understand the impact of sexual partners' characteristics on contraceptive decision-making. First, some studies predicting contraceptive use have included partner characteristics, but this work has been limited to men's reports of contra- ceptive use. ${ }^{21}$ Analysis of adult males' condom use suggests that partner's age, religion and education influence contraceptive use for pregnancy prevention. ${ }^{22}$ Among adolescent males, however, partner's age at last intercourse was not found to be related to condom use. ${ }^{23}$

Second, researchers have focused on differences between sexual partners, or social and demographic heterogamy. Levels of heterogamy may relate to relationship dynamics (e.g., communication and power), and as a consequence may influence contraceptive decision-making. The central aim of most of this work has been to test whether women who have sex with substantially older males (measured as age heterogamy) are less likely to practice contraception. In a clinic sample of women, age heterogamy was not related to consistent condom use. ${ }^{24}$ Yet national data show that at the bivariate level, extreme age gaps between teenage women and their most recent sexual partner are associated with lower levels of contraceptive use. ${ }^{25}$ Heterogamy based on race was not associated with condom use among adolescent males. ${ }^{26}$

Most prior research on young women's contraceptive use has focused on individual-level factors (e.g., religiosity, family structure, risk behaviors and academic performance) and has not examined their sexual partner's influence on contraceptive use. Analysis of the context of adolescent sexual relationships has actually been conducted more often from the male than from the female perspective. This article contributes to our understanding of men's roles in contraceptive decision-making by emphasizing the relationship context, defined as the type of relationship between sexual partners and the partner's social and demographic characteristics. Unlike prior research, we rely on a nationally representative sample of adolescent women to evaluate how the relationship between sexual partners at first intercourse influences whether contraception is practiced and what type of contraceptive is selected. We then assess whether the first sexual partner's social and demographic characteristics influence the contraceptive method used at first intercourse.

\section{Data and Methods \\ Data}

We drew our analytic sample from the 1995 National Survey of Family Growth (NSFG). The NSFG is a nationally representative sample of 10,847 women aged 15-44. These data are appropriate for our purposes for three reasons. First, the data provide information about women's relationship with their first sexual partner. Second, the data include questions about the social and demographic characteristics of the first sexual partner. Third, information about other factors that may influence contraceptive choice at first sexual intercourse, such as birth control education, school or risk activities and family background, are included in the survey.

Because we were interested in how adolescent relationships influence contraceptive decisions, we limited our sample to women who had their first voluntary intercourse prior to age $18(\mathrm{~N}=5,632)$. We further confined our analytic sample to 1,671 women who were born since 1970 (or younger than age 25 at the time of the interview). This limitation allowed us to focus on women who had recently experienced their first intercourse and permitted us to include variables related to school-based activities. * We also limited the sample to respondents who provided complete information about key independent variables, resulting in a sample of 1,593 women. (The exclusion of these respondents represents less than $5 \%$ of the sample and does not shift the distribution across the dependent variables or other independent variables.) Standard imputation procedures did not seem appropriate for categorizing the type of relationship with first sexual partner.

Contraceptive use at first intercourse is important because pregnancies have been found to occur early in an adolescent's sexual experiences ${ }^{27}$ and patterns of contraceptive use at younger ages may influence later contraceptive decisions. ${ }^{28}$ We included in our analyses two dependent variables that measure contraceptive use at first intercourse. The first was whether a contraceptive was used at first intercourse. We included any method, even the least effective, as a form of birth control. The second measured the primary contraceptive method used at first intercourse (pill, condom or any other method); here the sample was limited to women who used some form of birth control at first intercourse $(\mathrm{N}=1,100)$. The number of adolescents who reported using both the pill and condoms was insufficient to support multivariate analyses, but we present bivariate findings for respondents in this category.

The primary independent variable is the type of relationship the respondent had with her first sexual partner. Respondents were asked, "At the time you

*Questions related to school activity were asked only of women younger than 25 at the time of the interview. 
Table 1. Percentage distribution of female adolescents, by contraceptive use at first intercourse, and percentage distribution of contraceptive users, by type of method used at first intercourse, all according to relationship type, 1995 National Survey of Family Growth

\begin{tabular}{lll|lrr|r}
\hline Relationship type & \multicolumn{2}{l|l}{ Contraceptive use $(\mathrm{N}=1,593)$} & \multicolumn{2}{l|}{ Type of contraceptive used $(\mathrm{N}=1,100)$} & \multirow{2}{*}{ Total } \\
\cline { 2 - 5 } & None & Some & Condom & Pill & Other & \\
\hline All & $\mathbf{3 0 . 9}$ & 69.1 & $\mathbf{7 5 . 2}$ & $\mathbf{1 6 . 7}$ & $\mathbf{8 . 1}$ & $\mathbf{1 0 0 . 0}$ \\
Just met & 51.7 & 48.3 & 62.8 & 25.2 & 12.0 & 100.0 \\
Just friends & 43.9 & 56.1 & 75.0 & 9.5 & 15.4 & 100.0 \\
Went out once in a while & 24.8 & 75.2 & 82.4 & 13.3 & 4.4 & 100.0 \\
Going steady & 23.6 & 76.4 & 75.4 & 16.5 & 8.1 & 100.0 \\
Engaged & 35.3 & 64.7 & 67.8 & 27.2 & 5.0 & 100.0 \\
\hline
\end{tabular}

Note: Ns are unweighted; percentages are weighted.

first had sexual intercourse, how would you describe your relationship with him? Would you say you had just met, were just friends, went out once in a while, were going together or going steady, or engaged?" These five response categories were coded as a series of dummy variables. This measure is based on the respondent's perception of her relationship. A limitation of this work is that the respondent's view of the relationship may shift as time passes, but the extent to which first sexual relationships are later recharacterized remains unknown. Unfortunately, the NSFG had no measure of how the respondent characterized the type of relationship precisely at the time of sexual onset.

We also examined other independent variables that have been found to be associated with contraceptive use. An important measure related to sexual activity and contraceptive use is age at first intercourse. We coded respondent's race or ethnicity into four groups: non-Hispanic black, non-Hispanic white, Hispanic and other. Family structure, which was measured one year prior to first intercourse, included the following categories: living with two biological parents; living with a stepparent; living with a single parent; and other. Mothers' and fathers' education was divided into less than 12 years of education, 12 years and more than 12 years. We included an additional category to indicate whether information on the educational level of a specific parent was missing. The respondent's religiosity at age 14 was measured by how frequently she attended religious services, with responses ranging on a five-point scale from never (one) to more than once per week (five). A dichotomous variable indicated whether the respondent grew up in a rural or urban area.

We included several measures of schoolrelated behaviors. An important advantage of the NSFG is that it enabled us to measure all of these activities prior to first sexual intercourse. Women who reported receiving higher grades in school may have had greater motivation to avoid pregnancies and to practice contraception at first intercourse. We included grades received in school as a continuous variable, with one indicating mostly As to nine indicating mostly Fs. As measures of risk, we included a dummy variable indicating whether the respondent smoked regularly prior to first intercourse and a dummy variable measuring whether the respondent was ever expelled or suspended from school. A central variable was whether the respondent had any birth control education in school prior to first intercourse.

The relationship between sex education and later contraceptive use is not conclusively established in the literature, but it appears that HIV and sex education programs are often associated with increased contraceptive use. ${ }^{29}$ The strength of the association seems to depend upon specific programmatic features. ${ }^{30} \mathrm{We}$ did not have measures of intensity or specific content of courses, so we simply coded birth control education as a dichotomous variable, indicating whether the respondent had exposure to such a course while in school.

Another important set of independent variables we included are the socioeconomic characteristics of the respondents' first sexual partner. These characteristics include race or ethnicity, age, education and religion. It is important to note that all of these measures are proxy reports of the partner's characteristics and may not represent the partner's actual characteristics. Yet respondents' perceptions of their partner's characteristics could be as influential as his actual characteristics. For the purpose of understanding contraceptive behavior, we assume that it matters more what a young woman believes about her partner than what true characteristics her partner possesses.

We used two complementary strategies to examine how partners' characteristics influence contraceptive use. First, we sim- ply included variables measuring the male's socioeconomic circumstances as independent variables. We used the same four racial categories (black, Hispanic, non-Hispanic white and other), and religiosity parallels the measure we used for main respondents. Education was divided into less than 12 years of schooling, 12 years and more than 12 years. (We did not include this variable in the final analyses because it was highly correlated with partner's age.)

Second, we analyzed partner's influence on contraceptive use by creating variables that measure social and demographic homogamy (or similarity) between the male and female sexual partner. Because previous research has turned attention to older male sexual partners and teenage pregnancy, ${ }^{31}$ we included dummy variables that indicate whether the partner was younger, the same age, 1-2 years older, 3-5 years older or six or more years older than the respondent. Race or ethnicity is simply a measure of whether the respondent and sexual partner are from the same racial and ethnic group. We also created measures of religious homogamy, but we ultimately excluded this variable from the final analyses because of missing data.

\section{Methods}

We used logistic regression to test models predicting whether a contraceptive was used. We used multinomial logistic regression to test our models that predict the type of contraceptive used at first intercourse. In the tables, we report the odds ratios, which represent the exponentiated value of the coefficients, and the standard errors.

Our analytic strategy is parallel for each of our dependent variables. We first test a zero-order model that includes only the variable measuring the relationship with the first sexual partner. The next model includes the characteristics of the respondent: age at first intercourse, race and ethnicity, and background characteristics. The third model incorporates the school-related measures, and in the final model we substitute the partner homogamy measures for the partner socioeconomic characteristics to evaluate whether they contribute to the fit of the models, and present the independent effects of these variables on contraceptive use.

\section{Results}

Approximately three in 10 young women used no method of contraception at first intercourse (Table 1). Roughly half (52\%) 
of teenagers who had just met their first sexual partner used no method, compared with almost one-quarter (24-25\%) who were going steady or who went out once in a while. Generally, greater proportions of adolescents in more casual relationships ("just met" or "just friends") than in more serious relationships did not use any method of contraception at first intercourse. Yet, a larger proportion of those who were engaged than those who were going steady or going out did not use a method at first intercourse.

An examination of methods used by teenagers who reported practicing contraception at first intercourse reveals that consistent with prior research, the most common contraceptive method used at first intercourse was the condom (used by $75 \%$ ). Seventeen percent relied on the pill; $10 \%$ of the sample used only the pill and $7 \%$ used both the pill and condoms (not shown). Almost all of the dual users reported the pill as their primary method. Interestingly, engaged couples most often reported dual use of the pill and condoms $(11 \%)$; when dual users were counted as condom users, $78 \%$ of engaged couples used condoms.

Of methods used, condoms were selected most frequently by adolescents who went out once in awhile (82\%) and least often by adolescents who were engaged $(68 \%)$ or who had just met their first sexual partner $(63 \%$, Table 1$)$. Women who had just met their first sexual partner or who were engaged to their first sexual partner chose the pill most often ( $25 \%$ and $27 \%$, respectively).

Most of the sample was going steady with their first sexual partner (74\%); only $2 \%$ were engaged (Table 2). A considerable share $(16 \%)$ had just met or were just friends.

The mean age of the respondents at first intercourse was 15 . The majority of the sample was white and reported living with two biological parents. Approximately three-quarters of the sample had a mother and a father who had a high school education or more. Respondents' sexual partners were on average almost 18 years old at the respondents' first intercourse, and most often partners were older than participants. Typically, the age gap at first intercourse was not large, averaging 1-3 years (not shown). The distribution of partner's race or ethnicity mirrors that of the females: Fewer than onefifth of respondents reported first sexual intercourse with someone from a different racial or ethnic group (Table 2).

Respondents' average grade was 3.4, which translates to almost halfway be- tween the categories of "mostly Bs" and "mostly Bs and Cs." Approximately threequarters of the sample had birth control education prior to sexual activity. (Most of the sexual partners had less than 12 years of education, often because they were still in high school. Therefore, we excluded this variable from the multivariate analyses due to its colinearity with age.)

Model 1 of the logistic regression estimates predicting contraceptive use at first sexual intercourse shows that adolescents who had just met their partner or who were just friends had significantly reduced odds of practicing contraception at first intercourse, compared with the odds for those who were going steady with their first partner (Table 3, page 108). Adolescents who had just met their first sexual partner had $65 \%$ lower odds of using contraceptives than did girls who were going steady with their first sexual partner. We found no significant differences in contraceptive use between respondents who were going steady and those who went out once in a while.

In Model 2, which includes the background covariates, the effects of partner relationship remain about the same as in the first model. Respondents who first had sex at age 13 or younger had lower odds of using a contraceptive than those who were 16-17. In addition, white women were more likely than black or Hispanic women to practice contraception at first intercourse. Adolescents living with a stepparent had lower odds of contraceptive use than those living with two biological parents. Women who had a mother or a father with a low level of education were less likely than teenagers who had one or both parents with 12 years of schooling to practice contraception at first intercourse. Religiosity while growing up and place of residence did not influence contraceptive use at first intercourse.

Addition of the traditional school and risk predictors (Model 3) shows that relationship with first sexual partner maintains a similar pattern of effects as found in the prior models. Smoking or being expelled from school were not significantly related to contraceptive use. Women who had birth control education prior to first intercourse were significantly more likely to practice contraception. Respondents who earned low grades had reduced odds of using a contraceptive at first intercourse.

When homogamy between the respondent and her first sexual partner is taken into account (Model 4), racial and ethnic heterogamy was not significantly associated with contraceptive use at first inter-
Table 2. Percentage distributions and mean (and standard deviation) of social and demographic characteristics of female adolescents and their partners at first intercourse $(\mathrm{N}=1,593)$ Characteristic $\%$

\section{Relationship type}

Just met

$\%$

Just met

2.9

Went out once in a while

12.6

Going steady

8.7

Engaged

73.9

Respondent's age at first sex

Mean (in years)

$15.2(1.4)$

Respondent's race/ethnicity

Hispanic

14.1

Black

Non-Hispanic white

26.4

Other

3.2

\section{Family type}

Two parents

Single parent

Stepparent

Other

Mother's education (in years)

$<12$

26.0

$12 \quad 42.2$

$>12$

Missing $\quad 1.3$

Father's education (in years)

$<12$

12

42.7

$>12$

34.8

Missing

Mean

Rural resident

Yes
No

88.3

Smoked before first sex

$\begin{array}{ll}\text { Yes } & 23.7 \\ & \end{array}$

$\begin{array}{ll}\text { No } & 76.3\end{array}$

Expelled before first sex

Yes $\quad 13.9$

$\begin{array}{ll}\text { No } & 86.1\end{array}$

Birth control education before first sex Yes $\quad 76.4$

No

Grades

Mean

Partner's age

Mean (in years)

Partner's race/ethnicity

Hispanic

14.3

Black

28.4

Non-Hispanic white

54.4

Other

Age difference

Same age

15.8

Partner<respondent

3.6

Partner>respondent

80.6

Ethnicity

Different $\quad 16.8$

Same

83.2

Total

100.0

Note: Ns are unweighted; percentages are weighted. 
Table 3. Odds ratios (and standard errors) from logistic regression analysis of use of contraceptives at first intercourse, by social and demographic characteristics included in model $(\mathrm{N}=1,593)$

\begin{tabular}{|c|c|c|c|c|}
\hline Characteristics & Model 1 & Model 2 & Model 3 & Model 4 \\
\hline \multicolumn{5}{|l|}{ Relationship type } \\
\hline Just met & $0.345^{*}(0.302)$ & $0.304^{*}(0.326)$ & $0.341^{*}(0.331)$ & $0.338^{*}(0.333)$ \\
\hline Just friends & $0.404^{*}(0.156)$ & $0.467^{\star}(0.167)$ & $0.478^{*}(0.169)$ & $0.485^{*}(0.170)$ \\
\hline Went out once in a while & $0.966(0.200)$ & $1.019(0.210)$ & $1.022(0.211)$ & $1.020(0.212)$ \\
\hline Going steady (ref) & 1.000 & 1.000 & 1.000 & 1.000 \\
\hline Engaged & $0.651(0.385)$ & $0.670(0.410)$ & $0.650(0.413)$ & $0.666(0.416)$ \\
\hline \multicolumn{5}{|l|}{ Age at first intercourse } \\
\hline$\leq 13$ & na & $0.532^{*}(0.186)$ & $0.686^{*}(0.194)$ & $0.681^{*}(0.197)$ \\
\hline $14-15$ & na & $0.918(0.127)^{\prime}$ & $0.997(0.130)$ & $1.0003(0.131)$ \\
\hline $16-17$ (ref) & na & 1.000 & 1.000 & 1.000 \\
\hline \multicolumn{5}{|l|}{ Race/ethnicity } \\
\hline Hispanic & na & $0.462^{*}(0.171)$ & $0.485^{*}(0.176)$ & $0.453^{*}(0.181)$ \\
\hline Black & na & $0.518^{*}(0.144)$ & $0.529^{*}(0.153)$ & $0.536^{*}(0.153)$ \\
\hline Non-Hispanic white (ref) & na & 1.000 & 1.000 & 1.000 \\
\hline Other & na & $0.859(0.339)$ & $0.819(0.341)$ & $0.695(0.359)$ \\
\hline \multicolumn{5}{|l|}{ Family type } \\
\hline Two parents (ref) & na & 1.000 & 1.000 & 1.000 \\
\hline Single parent & na & $0.860(0.151)$ & $0.863(0.153)$ & $0.861(0.154)$ \\
\hline Stepparent & na & $0.730 *(0.158)$ & $0.736(0.160)$ & $0.733^{*}(0.161)$ \\
\hline Other & na & $0.828(0.224)$ & $0.817(0.227)$ & $0.821(0.227)$ \\
\hline \multicolumn{5}{|c|}{ Mother's education (in years) } \\
\hline$<12$ & na & $0.603^{*}(0.146)$ & $0.628^{*}(0.148)$ & $0.633^{*}(0.148)$ \\
\hline 12 (ref) & na & 1.000 & 1.000 & 1.000 \\
\hline$>12$ & na & $1.298(0.148)$ & $1.286(0.149)$ & $1.283(0.149)$ \\
\hline Missing & na & $3.094(0.654)$ & $3.111(0.655)$ & $3.079(0.656)$ \\
\hline \multicolumn{5}{|c|}{ Father's education (in years) } \\
\hline$<12$ & na & $0.598^{*}(0.15$ & $0.592^{*}(0.158)$ & $0.596^{*}(0.158)$ \\
\hline 12 (ref) & na & 1.000 & 1.000 & 1.000 \\
\hline$>12$ & na & $1.012(0.152)$ & $0.952(0.154)$ & $0.941(0.155)$ \\
\hline Missing & na & $0.728(0.214)$ & $0.724(0.216)$ & $0.724(0.216)$ \\
\hline \multicolumn{5}{|l|}{ Religiosity } \\
\hline Mean & na & $1.031(0.044)$ & $1.024(0.045)$ & $1.028(0.045)$ \\
\hline \multicolumn{5}{|l|}{ Rural resident } \\
\hline Yes & na & $1.189(0.194)$ & $1.106(0.195)$ & $1.110(0.195)$ \\
\hline No (ref) & na & 1.000 & 1.000 & 1.000 \\
\hline \multicolumn{5}{|l|}{ Smoked before first sex } \\
\hline Yes & na & na & $0.988(0.150)$ & $0.973(0.151)$ \\
\hline No (ref) & na & na & 1.000 & 1.000 \\
\hline \multicolumn{5}{|l|}{ Expelled before first sex } \\
\hline Yes & na & na & $0.903(0.166)$ & $0.892(0.167)$ \\
\hline No (ref) & na & na & 1.000 & 1.000 \\
\hline \multicolumn{5}{|c|}{ Birth control education before first sex } \\
\hline Yes & na & na & $1.793^{*}(0.136)$ & $1.763^{*}(0.136)$ \\
\hline No (ref) & na & na & 1.000 & 1.000 \\
\hline \multicolumn{5}{|l|}{ Grades } \\
\hline Mean & na & na & $0.889 *(0.039)$ & $0.889^{*}(0.039)$ \\
\hline \multicolumn{5}{|l|}{ Age difference } \\
\hline Same ages & na & na & na & $1.149(0.171)$ \\
\hline Partner $<$ respondent & na & na & na & $0.888(0.321)$ \\
\hline Respondent>partner (ref) & na & na & na & 1.000 \\
\hline \multicolumn{5}{|l|}{ Race/ethnicity } \\
\hline Different & na & na & na & $1.335(0.174)$ \\
\hline Same (ref) & na & na & na & 1.000 \\
\hline $\begin{array}{l}-2 \text { log likelihood } \\
d f\end{array}$ & $\begin{array}{c}43.329 \\
4\end{array}$ & 192.860 & $\begin{array}{c}223.227 \\
24\end{array}$ & $\begin{array}{c}226.937 \\
27\end{array}$ \\
\hline
\end{tabular}

${ }^{*} \mathrm{p} \leq .05$. Notes: ref=reference group. na=not applicable.

course. Age heterogamy does not appear to be significantly related to contraceptive use net of the other covariates, unless the sexual partner is six or more years older than the respondent; adolescents who had their first sexual intercourse with men substantially older than themselves had lower odds of practicing contraception (not shown). When the measures of age and race or ethnicity of the first sexual partner were substituted for the homogamy measures, they did not significantly contribute, and there were no significant differences in their effects on contraceptive use.

In multinomial regression estimates of type of contraceptive method selected at first intercourse (Table 4), the contrast group is condom use, with odds ratios representing the odds of pill use rather than condom use at first intercourse, or the odds of other method use versus condom use. In the first model, the type of relationship with partner is not significantly related to the odds of selecting any particular contraceptive method, with one exception: Adolescents who were "just friends" with their first sexual partner had higher odds of using other methods of protection rather than the condom. The second model indicates similar effects, once other social and demographic variables were included in the model.

The variables that were associated with pill use versus condom use as first method were age at first sex, race, family type, mother's education level and school grades. Younger adolescents had lower odds of selecting the pill, while black teenagers, compared with their white counterparts, had higher odds of selecting this method. Adolescents from single-parent families were significantly more likely than those from households with two biological parents to choose the pill. Respondents whose mother had a low educational level had higher odds of selecting the pill than did those whose mother had 12 years of schooling. Birth control education prior to first intercourse was not significantly related to type of contraceptive used in the multivariate model. The inclusion of the dual-use category (pill and condom) does not alter the effects of the birth control education variable (not shown). Sexual partners' race and age, as well as the homogamy measures, were not associated with contraceptive choice.

\section{Discussion}

While a majority of young women in this sample reported that first intercourse occurred within the context of a romantic relationship, a considerable number indicated that they had "just met" or were "just friends" with their initial partner. Further, the logistic regression estimates predicting contraceptive use show that those young women who were not romantically involved with their partner had significantly lower odds than those who were going steady with their first partner of practicing contraception at first intercourse. These effects of partner context remained, even 
when traditional individual-level predictors (such as race, family structure, school achievement and involvement in other risk behaviors) were taken into account. Most research to date on young women's contraceptive use has not included the relationship with the sexual partner as a factor contributing to contraceptive use. Our findings underscore the potentially important role of relationships in framing adolescent sexual decisions.

Some limitations of the data used in this article point to the need for further research. First, the retrospective measure of relationship type may have had an impact on our findings. Young woman may recall their first sexual partner as more serious or less serious, depending on later relationships and sexual encounters, the way the first sexual relationship ended or pregnancy outcome. It is difficult to identify and ask adolescents about the nature of their relationship precisely when they had first intercourse. Yet this would avoid potential recall problems associated with identification of the nature of the relationship.

Additionally, the measures of relationship type may represent a somewhat narrow perspective. Future research is needed that specifies in greater detail how variations in relationship quality affect contraceptive use and the types of contraceptive methods that are used. For example, variations in perceived power may be an especially important dynamic to consider.

Another shortcoming is that we included a restricted number of male characteristics. Certainly, other characteristics beyond partner's age, religion and education may matter. A contribution of this research is that we considered asymmetries between sexual partners. For example, we examined the role of age heterogamy as a predictor of contraceptive use (and found that having first intercourse with significantly older men reduced the odds of practicing contraception, but did not influence the type of method used). However, it is quite possible that more subtle indicators of relationship asymmetries might influence these important outcomes.

Another type of asymmetry that we cannot address in this paper is each partner's description of the relationship. Considerable levels of asymmetry between partners on the nature of their relationship have been reported. ${ }^{32}$ Asymmetry in sexual partners' perception of their relationship could influence contraceptive decision-making. Obtaining such couple-level data from sexual partners may be quite

Table 4. Odds ratios (and standard errors) from multinomial logistic regression analysis of type of contraceptive used at first intercourse, by social and demographic characteristics $(\mathrm{N}=1,100)$

\begin{tabular}{|c|c|c|c|c|}
\hline \multirow[t]{2}{*}{ Characteristic } & \multicolumn{2}{|l|}{ Model 1} & \multicolumn{2}{|l|}{ Model 2} \\
\hline & Pill vs. condom & Other vs. condom & Pill vs. condom & Other vs. condom \\
\hline \multicolumn{5}{|l|}{ Relationship type } \\
\hline Just met & $1.880(0.496)$ & $1.463(0.767)$ & $2.093(0.519)$ & $1.148(0.812)$ \\
\hline Just friends & $0.506(0.364)$ & $2.231 *(0.298)$ & $0.524(0.375)$ & $2.403^{\star}(0.312)$ \\
\hline Went out once in a while & $0.969(0.283)$ & $0.798(0.444)$ & $0.933(0.297)$ & $0.862(0.452)$ \\
\hline Going steady (ref) & 1.000 & 1.000 & 1.000 & 1.000 \\
\hline Engaged & $1.688(0.534)$ & $0.788(1.046)$ & $1.185(0.564)$ & $1.073(1.070)$ \\
\hline \multicolumn{5}{|l|}{ Age } \\
\hline$\leq 13$ & na & na & $0.246^{*}(0.397)$ & $0.648(0.474)$ \\
\hline $14-15$ & na & na & $0.473^{*}(0.191)$ & $0.973(0.251)$ \\
\hline $16-17$ (ref) & na & na & 1.000 & 1.000 \\
\hline \multicolumn{5}{|l|}{ Race/ethnicity } \\
\hline Hispanic & na & na & $0.563(0.355)$ & $1.481(0.345)$ \\
\hline Black & na & na & $1.999^{\star}(0.219)$ & $0.893(0.342)$ \\
\hline Non-Hispanic white (ref) & na & na & 1.000 & 1.000 \\
\hline Other & na & na & $2.215(0.469)$ & $6.457^{*}(0.433)$ \\
\hline \multicolumn{5}{|l|}{ Family type } \\
\hline Two parents (ref) & na & na & 1.000 & 1.000 \\
\hline Single parent & na & na & $1.776^{*}(0.216)$ & $0.618(0.335)$ \\
\hline Step-parent & na & na & $1.244(0.236)$ & $0.53(0.359)$ \\
\hline Other & na & na & $1.149(0.386)$ & $1.12(0.447)$ \\
\hline \multicolumn{5}{|c|}{ Mother's education (in years) } \\
\hline$<12$ & na & na & $1.640^{*}(0.224)$ & $1.078(0.353)$ \\
\hline 12 (ref) & na & na & 1.000 & 1.000 \\
\hline$>12$ & na & na & $0.782(0.211)$ & $1.384(0.267)$ \\
\hline Missing & na & na & $1.288(0.681)$ & $1.981(0.818)$ \\
\hline \multicolumn{5}{|c|}{ Father's education (in years) } \\
\hline$<12$ & na & na & $0.912(0.244)$ & $0.943(0.355)$ \\
\hline 12 (ref) & na & na & 1.000 & 1.000 \\
\hline$>12$ & na & na & $0.743(0.216)$ & $0.976(0.285)$ \\
\hline Missing & na & na & $0.515(0.370)$ & $1.712(0.441)$ \\
\hline \multicolumn{5}{|l|}{ Religiosity } \\
\hline Mean & na & na & $0.959(0.066)$ & $1.107(0.089)$ \\
\hline \multicolumn{5}{|l|}{ Rural resident } \\
\hline Yes & na & na & $1.562(0.253)$ & $0.523(0.454)$ \\
\hline No (ref) & na & na & 1.000 & 1.000 \\
\hline \multicolumn{5}{|l|}{ Smoked before first sex } \\
\hline Yes & na & na & $1.072(0.219)$ & $1.041(0.283)$ \\
\hline No (ref) & na & na & 1.000 & 1.000 \\
\hline \multicolumn{5}{|l|}{ Expelled before first sex } \\
\hline Yes & na & na & $1.195(0.248)$ & $0.729(0.408)$ \\
\hline No (ref) & na & na & 1.000 & 1.000 \\
\hline \multicolumn{5}{|c|}{ Birth control education before first sex } \\
\hline Yes & na & na & $0.747(0.224)$ & $0.868(0.299)$ \\
\hline No (ref) & na & na & 1.000 & 1.000 \\
\hline \multicolumn{5}{|l|}{ Grades } \\
\hline Mean & na & na & $1.190^{*}(0.060)$ & $1.183^{*}(0.082)$ \\
\hline
\end{tabular}

${ }^{*} \mathrm{p} \leq .05$. Note: $n a=$ not applicable.

difficult, particularly among those who did not know their partner well.

Finally, these results focus on adolescent females. Prior work using nationally representative samples to examine the relationship context of adolescents has been limited to males. An important next step is to evaluate whether the effects of relationships on sexual behaviors are the same for adolescent boys and girls. Data collected from both adolescent boys and girls are required to make such comparisons.
The present findings have implications for the design of programs focused on sexuality and contraception during adolescence. Our findings support the social influence model of health behavior, by moving beyond individualistic models and emphasizing the importance of relationships with potential sexual partners on risktaking behavior. ${ }^{33}$ Clearly, programs could be strengthened if more attention were paid to the relationship context in which sexual and contraceptive decision-making oc- 
curs. Some argue that the latest generation of sex and AIDS education programs are lacking because "relatively little time was spent on addressing other sexuality issues, such as gender roles, dating and parenthood." ${ }^{\prime 34}$ Certainly, some of the most effective programs include these elements, as well as the social influence of others, and offer role-playing strategies to reduce the effects of social pressure. ${ }^{35}$ A curriculum that includes a thorough discussion of emotional and situational factors would be an important supplement to informationbased approaches. Our results indicate that adolescents who are not romantically involved may be unprepared for the outcome of a sexual advance. A relationship-oriented approach could be used as a springboard for an effective, lively group discussion that explores underlying reasons for this pattern of results (e.g., feelings of embarrassment, little time to develop effective couple communication or concerns about reputation). It is likely that young people would respond more readily to a relationship focus than to more simple clinical treatments of these topics.

\section{References}

1. Abma JA et al., Fertility, family planning and women's health: new data from the 1995 National Survey of Family Growth, Vital and Health Statistics, 1997, Series 23, No. 19; and Resnick $\mathrm{M}$ et al., Protecting adolescents from harm: findings from the National Longitudinal Study on Adolescent Health, Journal of the American Medical Asso ciation, 1997, 278(10):823-832.

2. Kann LS et al., Youth risk behavior surveillance-United States, 1997, Journal of School Health, 1998, 68(9): 355-369.

3. Abma JA et al., 1997, op. cit. (see reference 1); and Murphy $\mathrm{J}$ and Boggess S, Increased condom use among teenage males, 1988-1995: the role of attitudes, Family Plan ning Perspectives, 1998, 30(6):276-280 \& 303.

4. Abma JA et al., 1997, op. cit. (see reference 1); and Sonenstein F, Pleck J and Ku L, Levels of sexual activity among adolescent males in the United States, Family Plan ning Perspectives, 1991, 23(4):162-167.

5. Longmore $\mathrm{M}$, Manning $\mathrm{W}$ and Giordano $\mathrm{P}$, Parenting strategies and sequencing of adolescents' dating and sexual initiation: a longitudinal analysis, paper presented at the annual meeting of the Population Association of America, Chicago, April 2-4, 1998; Miller BC et al., The timing of sexual intercourse among adolescents: family, peer, and other antecedents, Youth and Society, 1997, 29(1):54-83; and Thornton A, The courtship process and adolescent sexuality, Journal of Family Issues, 1990, 11(3):239-273.

6. Moore KA et al., Adolescent Sex, Contraception, and Childbearing: A Review of Recent Research, Washington, DC: Child Trends, June 1995.

7. Inazu J, Partner involvement and contraceptive efficacy in premarital sexual relationships, Population and Environment, 1987, 9(4):225-237; and Pleck J, Sonenstein $\mathrm{F}$ and Swain S, Adolescent males' sexual behavior and contraceptive use: implications for male responsibility, Journal of Adolescent Research, 1988, 3(3-4):275-284.

8. Thompson L and Spanier GB, Influence of parents, peers, and partners on the contraceptive use of college men and women, Journal of Marriage and the Family, 1978, 40(3):481-492.

9. Landry D and Camelo T, Young unmarried men and women discuss men's role in contraceptive practice, Fam ily Planning Perspectives, 1994, 26(5):222-227.

10. Pleck J, Sonenstein F and Swain S, 1988, op. cit. (see reference 7).

11. Santelli J et al., Stage of behavior change for condom use: the influence of partner type, relationship and pregnancy factors, Family Planning Perspectives, 1996, 28(3): 101-107.

12. Darroch J, Landry D and Oslak S, Age differences between sexual partners, Family Planning Perspectives, 1999, 31(4):160-167.

13. Adler NL and Hendrick SS, Relationships between contraceptive behavior and love attitudes, sex attitudes, and self-esteem, Journal of Counseling and Development, 1991, 70(2):302-308.

14. $\mathrm{Ku} \mathrm{L}$, Sonenstein $\mathrm{F}$ and Pleck J, The dynamics of young men's condom use during and across relationships, Family Planning Perspectives, 1994, 26(6):246-251.

15. Thompson L and Spanier GB, 1978, op. cit. (see reference 8)

16. Pleck J, Sonenstein F and Ku L, Adolescent males' condom use: relationships between perceived cost-benefits and consistency, Journal of Marriage and the Family, 1991, 53(3):733-745.

17. Weisman CS et al., Consistency of condom use for disease prevention among adolescent users of oral contraceptives, Family Planning Perspectives, 1991, 23(2):71-74.

18. Ku L, Sonenstein F and Pleck J, 1994, op. cit. (see reference 14).

19. Forste R and Morgan K, How relationships of U.S. men affect contraceptive use and efforts to prevent sex- ually transmitted diseases, Family Planning Perspectives, 1998, 30(2):56-62.

20. Landry D and Camelo T, 1994, op. cit. (see reference 9).

21. Forste R and Morgan K, 1998, op. cit. (see reference 19); and Ku L, Sonenstein F and Pleck J, 1994, op. cit. (see reference 14$)$.

22. Forste R and Morgan K, 1998, op. cit. (see reference 19).

23. Ku L, Sonenstein F and Pleck J, 1994, op. cit. (see reference 14).

24. Weisman CS et al., 1991, op. cit. (see reference 17).

25. Darroch J, Landry D and Oslak S, 1999, op. cit. (see reference 12 ).

26. Ku L, Sonenstein F and Pleck J, 1994, op. cit. (see reference 14).

27. Zabin LS, Kantner JF and Zelnik M, The risk of adolescent pregnancy in the first months of intercourse, Fam ily Planning Perspectives, 1979, 11(4):215-222.

28. Ku L, Sonenstein F and Pleck J, 1994, op. cit. (see reference 14).

29. Kirby D and DiClemente RJ, School-based interventions to prevent unprotected sex and HIV among adolescents, in: DiClemente RJ and Peterson JL, eds., Pre venting AIDS: Theories and Methods of Behavioral Interventions, New York: Plenum Press, 1994, pp.117-140.

30. Frost JJ and Forrest JD, Understanding the impact of effective teenage pregnancy prevention programs, Fam ily Planning Perspectives, 1995, 27(5):188-195; Kirby D and DiClemente RJ, 1994, op. cit. (see reference 29); and Kirby D and Coyle K, School-based programs to reduce sexual risk-taking behavior, Children and Youth Services Review, 1997, 19(5-6):415-436.

31. Darroch J, Landry D and Oslak S, 1999, op. cit. (see reference 12); Lindberg LD et al., Age differences between minors who give birth and their adult partners, Family Planning Perspectives, 1997, 29(2):61-66; and Landry DJ and Forrest JD, How old are US fathers? Family Planning Perspectives, 1995, 27(4):159-165.

32. Carver K and Udry JR, Reciprocity in the identification of adolescent romantic partners, paper presented at the annual meeting of the Population Association of America, Washington, DC, March 28, 1997.

33. Friedan SR, Des Jarlais DC and Ward TP, Social models for changing health-relevant behavior, in DiClemente RJ and Peterson JL, eds., Preventing AIDS: Theories and Methods of Behavioral Interventions, New York: Plenum Press, 1994, pp. 95-116.

34. Kirby D and DiClemente RJ, 1994, op. cit. (see reference 29).

35. Ibid. 